\title{
Heat Shock Protein 60 in Hepatocellular Carcinoma: Insights and Perspectives
}

\author{
Abdullah Hoter ${ }^{1,2 *}$, Sandra Rizk ${ }^{3}$ and Hassan Y. Naim ${ }^{1}$ \\ ${ }^{1}$ Department of Physiological Chemistry, University of Veterinary Medicine Hannover, Hanover, Germany, ${ }^{2}$ Department \\ of Biochemistry and Chemistry of Nutrition, Faculty of Veterinary Medicine, Cairo University, Giza, Egypt, ${ }^{3}$ Department \\ of Natural Sciences, Lebanese American University, Byblos, Lebanon
}

OPEN ACCESS

Edited by:

Antonella Marino Gammazza,

University of Palermo, Italy

Reviewed by:

Everly Conway de Macario,

University of Maryland, Baltimore,

United States

Jason C. Young,

McGill University, Canada

*Correspondence:

Abdullah Hoter

abdullah.hoter@tiho-hannover.de;

abdullah.hoter@vet.cu.edu.eg

Specialty section:

This article was submitted to

Protein Folding, Misfolding

and Degradation,

a section of the journal

Frontiers in Molecular Biosciences

Received: 04 February 2020

Accepted: 23 March 2020

Published: 15 April 2020

Citation:

Hoter A, Rizk S and Naim HY (2020) Heat Shock Protein 60 in Hepatocellular Carcinoma: Insights and Perspectives.

Front. Mol. Biosci. 7:60. doi: 10.3389/fmolb.2020.00060
Heat shock protein 60 (HSP60) is a mitochondrial chaperone that is implicated in physiological and pathological processes. For instance, it contributes to protein folding and stability, translocation of mitochondrial proteins, and apoptosis. Variations in the expression levels of HSP60 have been correlated to various diseases and cancers, including hepatocellular carcinoma (HCC). Unlike other HSPs which clearly increase in some cancers, data about HSP60 levels in HCC are controversial and difficult to interpret. In the current review, we summarize and simplify the current knowledge about the role of HSP6O in HCC. In addition, we highlight the possibility of its targeting, using chemical compounds and/or genetic tools for treatment of HCC.

Keywords: heat shock proteins, hepatocellular carcinoma, cancer therapy, chaperones, therapeutic resistance, chaperonin

\section{INTRODUCTION}

Hepatocellular carcinoma (HCC) is a common cancer of the liver with worldwide incidence and high mortalities. According to 2018 statistics, HCC is estimated to be the sixth frequently diagnosed cancer and the fourth main cause of death globally (Bray et al., 2018). Notably, the morbidity and mortality rates in men are two-threefold greater than in women. Moreover, HCC represents the most common cancer in 13 geographically diverse nations including countries from Africa like Egypt, Gambia, and Guinea as well as countries from Eastern and South-Eastern Asia such as Mongolia, Cambodia, and Vietnam. Some reports highlight the spread of the disease among developed countries despite the advances in vaccine development (Stasi et al., 2016; Ghouri et al., 2017). Several risk factors lead to HCC development and contribute to its complex pathogenesis such as chronic viral infections including hepatitis $B$ virus (HBV) and hepatitis $\mathrm{C}$ virus $(\mathrm{HCV})$, alcoholic cirrhosis, non-alcoholic steatohepatitis (NASH), exposure to chemical carcinogens, and ingestion of aflatoxin-contaminated foods (Fujiwara et al., 2018) (Figure 1).

Heat shock proteins (HSPs) are a set of evolutionarily conserved molecules which exist in almost all living organisms (Lindquist and Craig, 1988; Jäättelä, 1999; Sørensen et al., 2003; Chen et al., 2018). Generally, these numerous proteins are classified into families and subfamilies of distinct molecular masses that range from about 10 to $110 \mathrm{kDa}$. The families of HSPs are grouped into large HSPs such as HSP110 and glucose-regulated protein 170 (GRP170), small HSPs (sHSPs) besides HSP40 (DNAJ), chaperonin, or heat shock protein 60 (HSP60), HSP70, and HSP90 (Kampinga et al., 2009; Chatterjee and Burns, 2017). Members of HSPs are commonly known to function as molecular chaperones assisting in the folding of newly synthesized as well as misfolded proteins. 
In addition, they are involved in the elimination of terminally misfolded proteins through their targeting to cellular proteolytic machineries (Hartl et al., 2011; Hipp et al., 2019).

HSP60 (also called Cpn60) is a ubiquitous chaperone present in all mammalian cells and tissues including liver. This HSP performs many physiological functions that are not restricted to its cellular canonical location in the mitochondria (Gupta et al., 2008; Merendino et al., 2010). It supports mitochondrial protein folding and assists in proteolytic degradation of denatured or aberrantly folded proteins in an ATP-dependent fashion (Azem et al., 1995; Henderson et al., 2013). HSP plays numerous physiological roles but can also be pathogenic in various conditions, including cancer and neurodegenerative diseases (Cappello et al., 2008; Bross et al., 2012; Zhou et al., 2018). Recent reports highlight the role and implication of HSP60 in human cancer development and management whereby its targeting has revealed promising therapeutic outcomes (Pace et al., 2013; Li et al., 2014; Meng et al., 2018).

HSP60 has been studied as biomarker for diagnosis and prognosis assessment and as therapeutic agent in a range of diseases, such as gastric (Li et al., 2014), bronchial (Cappello et al., 2005), colorectal (Hamelin et al., 2011) and ovarian cancer (Guo et al., 2019), as well as glioblastoma (Khalil and James, 2007) and esophageal squamous cell carcinoma (Faried et al., 2004). Nevertheless, the role of HSP60 in HCC remains poorly understood. In the current review, we discuss the oncogenic role of HSP60 and its potential as therapeutic target, focusing on HCC. Moreover, we shed the light on the potential of HSP60 targeting as a therapeutic strategy to combat HCC.

\section{STRUCTURAL AND ORGANIZATIONAL ASPECTS OF HUMAN HSP60}

Generally, the term HSP60 refers to the mtHSP60 while the cytosolic homolog is known as TRiC/CCT. There is a notion that mtHSP60 arose from bacterial ancestors that were engulfed by early eukaryotic cells to produce the mitochondrial organelle (Hemmingsen et al., 1988). Mechanistically, HSP60 (HSPD1) forms tetradecamers consisting of two stacked heptameric rings with a central cavity that harbors the client protein. Importantly, HSPE1 (the homolog of bacterial GroES and known as HSP10) forms a single heptameric ring that functions as a cap for the HSPD1 assembly. This structural organization is essential for the ATP-dependent functionality of HSP60 in protein folding (Pace et al., 2013; Nisemblat et al., 2015; Okamoto et al., 2015). On the other hand, the cytosolic TRiC/CCT consists of eight subunits encoded by TCP1 and CCT2-8 genes and has its own built-in cap system (Leitner et al., 2012). In human, HSP60 is encoded by a gene located on chromosome 2q33.1 (Hansen et al., 2003). hHSP60 resides mostly in the mitochondrial matrix and the outer mitochondrial membrane with potential localization to other extra-mitochondrial sites (Soltys and Gupta, 1999; Gupta et al., 2008). Despite its constitutive expression under physiological conditions, increased levels of HSP60 can be induced following mitochondrial damage or heat stress.

In this manuscript, we use the word expression and its derivatives to indicate presence or quantitative changes of any protein, e.g., Hsp60, indiscriminately, without considering the cause, namely whether they are due to changes in the levels of expression of the pertinent gene, or to post-transcriptional or post-translational mechanisms, or a combination of them. Like most HSPs, hHSP60 is regulated via heat shock response by binding of the heat shock element (HSE) to the specific region on the DNA (Hansen et al., 2003). It should be noted that increasing reports correlate the variant expression of hHSP60 in different cellular compartments as well as biological fluids, including blood and cerebrospinal fluid, to human pathological conditions (Deocaris et al., 2006). Hence, detection and quantitative determination of HSP60 alterations may provide clues for studying disease mechanisms, prognosis, and treatment progress (Nakamura and Minegishi, 2013).

\section{THE ANTI-APOPTOTIC AND ONCOGENIC ROLES OF HSP60}

An interesting activity of HSP60 in mammalian cells is its contribution to apoptosis regulation. Early studies in the leukemic Jurkat T cell line revealed that HSP60 and its associated chaperone HSP10 form a complex with caspase-3 leading to its maturation. This observation suggested a potential chaperoning activity of HSP60 toward caspase-3 (Samali et al., 1999; Xanthoudakis et al., 1999). In addition, other studies showed that HSP60 was expressed on the surface of murine lymphoma cells (Sapozhnikov et al., 1999). Moreover, HSP60 has been linked to tumor cell apoptosis in a process that involves increased surface expression of HSP60 and subsequent stimulation of antitumor immune responses (Feng et al., 2001). On the other hand, increased expression of HSP60 in cardiac myocytes has been found to inhibit apoptosis indicating a significant yet complex role of HSP60 in the apoptotic machinery of tumor cells (Henderson et al., 2013). These findings in tumor and nontumor cells raised many questions whether HSP60 is an antior pro-apoptotic protein (Henderson et al., 2013). Importantly, the previous study that included many in vitro apoptotic systems could unravel some mechanistic lines of HSP60 apoptotic action (Chandra et al., 2007). One significant conclusion was that the cytosolic accumulation of HSP60 is a common process during apoptosis regardless of its mitochondrial release and its pro-survival or pro-apoptotic behavior involves differential interactions with caspase-3 (Chandra et al., 2007).

Owing to its anti-apoptotic properties, it is not surprising that HSP60 displays tumorigenic functions. HSP60 supports cancer development via increasing tumor growth, promoting angiogenesis and metastasis, reducing mitochondrial permeability transition, and counteracting apoptosis (Wu et al., 2017). In accordance with these functions, secretion of HSP60 has been described in all investigated tumor cells suggesting a role in tumor growth and dissemination, where the secretion process was independent of cell death (Merendino 


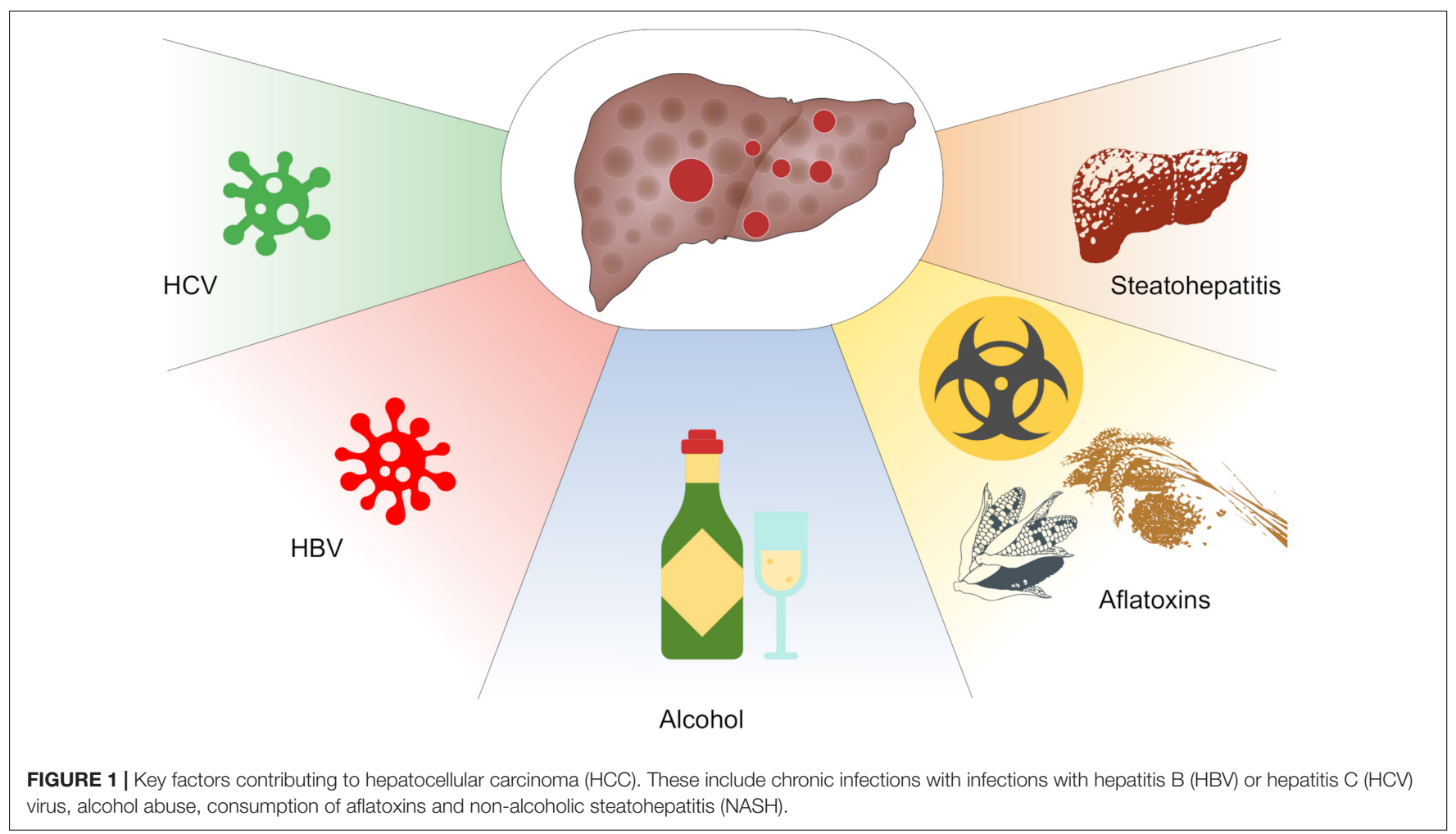

et al., 2010). Further molecular investigations revealed that pro-carcinogenic effects of HSP60 are due to its ability to enhance cancer cell survival via interacting with and inhibiting the intracellular isoform of clusterin in neuroblastoma cells (Chaiwatanasirikul and Sala, 2011).

Suppression of apoptosis by HSP60 is concomitant with overexpression of the anti-apoptotic proteins $\mathrm{Bcl}-2, \mathrm{Bcl}-\mathrm{xL}$, and survivin, maintenance of the mitochondrial transmembrane potential, and inhibition of caspase 3 activation (Deocaris et al., 2006). Cytosolic HSP60 inhibits the translocation of the pro-apoptotic protein Bax into the mitochondria, hence promoting cell survival (Xanthoudakis et al., 1999; Lianos et al., 2015). Furthermore, the anti-apoptotic actions of HSP60 involve its interaction with several molecules including the mitochondrial HSP70, survivin, and p53. HSP60 is also a potent regulator of the mitochondrial permeability transition which is meditated through a multichaperone complex comprising HSP60, HSP90, and tumor necrosis factor receptor-associated protein-1 (TNFRP1), particularly assembled in tumors but not in normal cells (Ghosh et al., 2010; Rodríguez et al., 2016) (Figure 2). In tumor cells, the anti-apoptotic HSP60 has been found to interact with cyclophilin D in the mitochondrial permeability transition pore where subsequent disruption of this interaction altered the mitochondrial permeability transition, stimulated caspasedependent apoptosis, and led to suppression of tumor cell growth (Ghosh et al., 2010).

Interestingly, inhibition of HSP60 could enhance the tumor suppressive activity of insulin-like growth factor binding protein 7 (IGFBP7) in colorectal cancer cells (Ruan et al., 2010). In human cancer HeLa cells, cytosolic HSP60 has been shown to support nuclear factor-kB (NF-kB)-dependent survival through binding and regulating the activity of IkB kinase (IKK) (Chun et al., 2010). Moreover, HSP60 knockdown in ovarian cancer cells inhibits tumor progression by breaking mitochondrial proteostasis, and inactivating the mTOR pathway (Guo et al., 2019). With regard to cancer metastasis, HSP60 has been described as a key chaperone that promotes metastatic phenotypes both in vitro and in vivo (Tsai et al., 2009). This effect is attributed to a significant interaction between HSP60 and $\beta$-catenin resulting in overexpression of $\beta$-catenin and enhancement of its transcriptional activity (Tsai et al., 2009).

Upregulation of HSP60 has been implicated in cervical cancer progression and prognosis (Hwang et al., 2009). Likewise, expression of HSP60 has been linked to the progression of prostate cancer (Castilla et al., 2010; Hoter et al., 2019). In ovarian cancer, the HSP60 transcript levels were variable in cancerous tissues. However, several reports linked high HSP60 expression to advanced ovarian cancer stages highlighting its prognostic value (Kimura et al., 1993; Hjerpe et al., 2013; Hoter and Naim, 2019). In breast cancer, autoantibodies against HSP60 have been reported to be elevated and their levels were remarkably associated with cancer grade (Hamrita et al., 2008). Sera obtained from patients with colorectal cancer showed increased concentrations of HSP60 that were associated with advanced stages of colorectal cancer (Hamelin et al., 2011). These findings strengthen the notion of utilizing HSP60 as a diagnostic and prognostic marker in several types of cancers. 


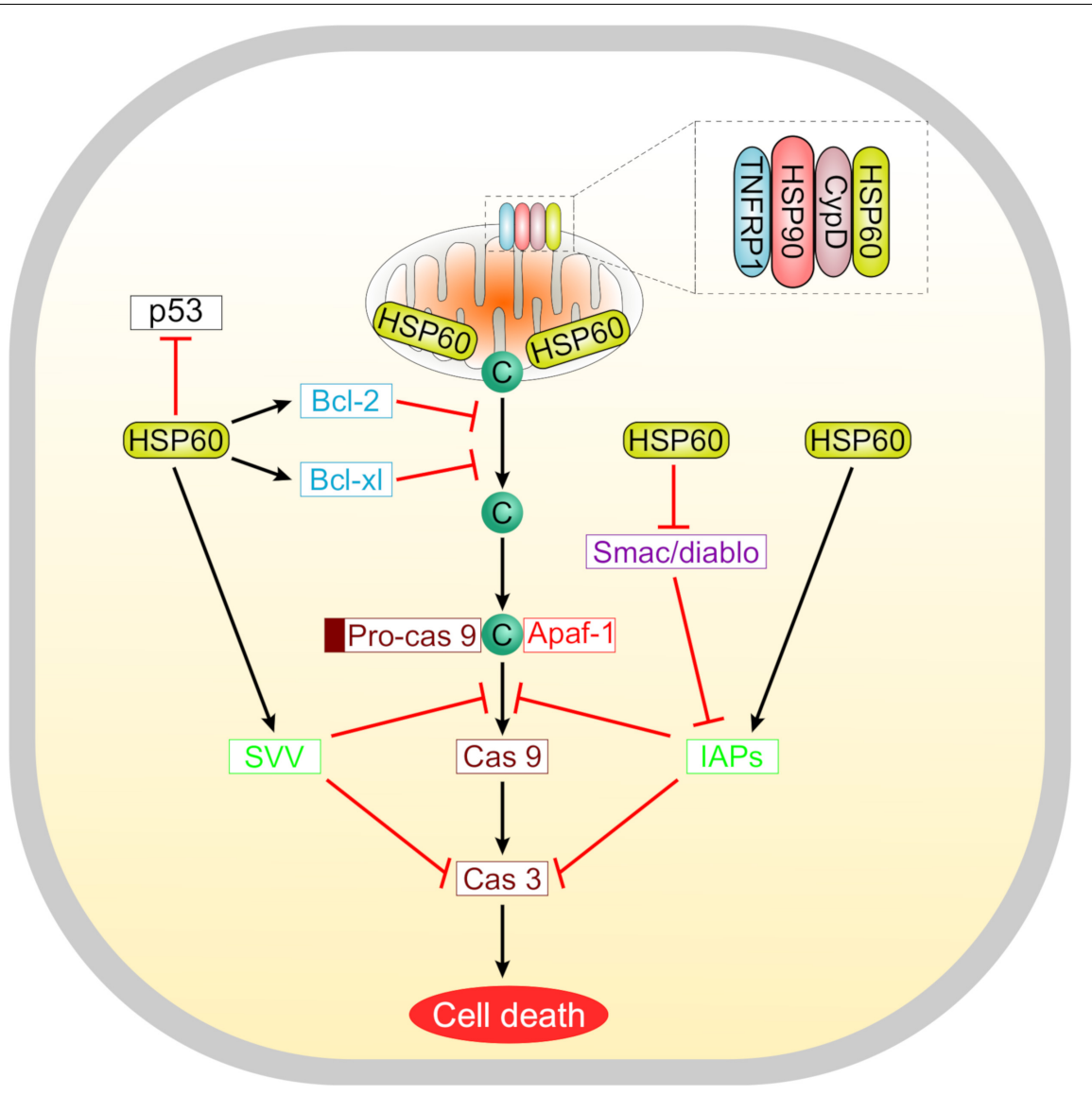

FIGURE 2 | A schematic representation summarizing the roles of HSP60 in regulating tumor cell apoptosis. Suppression of apoptosis by HSP60 is associated with increased levels of anti-apoptotic proteins like Bcl-2, Bcl-xL, and survivin. These molecules counteract the release of cytochrome c from mitochondria. Selectively in tumor cells, HSP60 forms a multichaperone complex with Cyclophilin D (Cyp D) and other chaperones including HSP90 and tumor necrosis factor

receptor-associated protein 1 (TNFRP1) to maintain the mitochondrial permeability transition. Oncogenic HSP60 interacts with p53 in tumor cells and suppresses its action. HSP60 also controls the progression of apoptosis via regulating the mitochondrial release of smac/diablo and controlling the function of inhibitor of apoptosis (IAP) family proteins that inhibit caspases.

\section{HSP60 IS A KEY PLAYER IN MAJOR ETIOLOGIES OF HCC}

In-depth analyses of the etiologies leading to HCC reveal that HSP60 plays a yet unclear role in diverse causalities of HCC development. HSP60 is implicated in the predisposing factors of HCC including HBV, HCV, and alcoholic hepatitis as described in the next section.

\section{HSP60 IN HEPATITIS B VIRUS (HBV) INFECTION}

HBV infection is a major risk factor for the development of HCC worldwide. Chronic infection with $\mathrm{HBV}$ predisposes patients with cirrhotic liver or those devoid of hepatic cirrhotic lesions to HCC (Xu et al., 2014). Notably, the central burden of the HCC $(85 \%)$ is noticed in the HBV endemic regions (Niu and Hann, 2017). Initial studies demonstrated that HSP60 interacts with human $\mathrm{HBV}$ polymerase leading to its maturation into its active form (Park and Jung, 2001; Park et al., 2002). Moreover, other studies showed that the transcriptional transactivating protein HBx of HBV form a complex with HSP60 and HSP70 suggesting their contribution to virus-mediated liver oncogenesis (Zhang et al., 2005). In line with previous findings, comparative proteomic analysis of liver HepG2.2.15 cell line revealed that HSP60 forms, together with HSP70 and HSP90, a chaperone complex that is suggested to influence $\mathrm{HBV}$ production and secretion (Liu et al., 2009). Furthermore, targeted therapy toward HSP60 using antisense oligonucleotide greatly interferes with HBV replication (Park et al., 2003).

\section{HSP6O IN HEPATITIS C VIRUS (HCV) INFECTION}

Similar to its role in HBV infection, HSP60 has been found to mediate HCV infection in several aspects. HSP60 has been demonstrated to interact with the $\mathrm{N}$-terminal domain of the core structural protein of $\mathrm{HCV}$ which is involved in $\mathrm{HCV}$ 
chronic infection-associated liver diseases (Kang et al., 2009). The HSP60-HCV interaction has been found to mediate the production of reactive oxygen species (ROS) and regulate apoptosis. Moreover, high expression of HSP60 in human liver cells expressing the HCV core protein could protect against TNF- $\alpha$ induced cell lethality via reduction of ROS production (Kang et al., 2009).

\section{HSP60 IN ALCOHOLIC HEPATITIS}

Initial studies showed that HSP60 levels were increased in liver tissues of patients with acute alcoholic liver. Additionally, raised circulating anti-HSP60 IgA levels have been reported. These findings suggest that overall upregulation of HSP60 in tissues and serum might be one of the pathogenic mechanisms leading to the development and progression of liver damage in alcoholic hepatitis (Koskinas et al., 1993). In accordance with these results, other research groups reported a strong association between IgA levels against HSP60 and patients with acute alcoholic hepatitis (Winrow et al., 1994).

\section{HSP60 IN HCC}

Early studies showed that the expression of HSP60 was highly increased in chronic active hepatitis with preferential accumulation in areas of inflammatory infiltrates (Lohse et al., 1993). Several proteomic and immunohistochemical analyses revealed upregulation of a multitude of chaperones including HSP60 in HCC (Lim et al., 2002, 2005; Kim et al., 2003). Recent reports showed that both blood and urine mRNA levels of HSP60 were significantly higher in HCC post-HCV patients compared with those having cirrhosis or healthy controls (Abd El-Salam et al., 2017). Moreover, proteomic analysis of HCC tumor associated antigens has identified HSP60 as an important HCC marker. Further serological investigations revealed that HSP60 could be detected not only in sera of HCC patients but also in patients with chronic hepatitis and liver cirrhosis (Looi et al., 2008). With reference to recent meta-analysis performed on patients with digestive cancers, HSP60 has been considered an advanced biomarker for HCC (Chen et al., 2019).

Molecular studies revealed that the redox status of HSP60 is crucial in the hepatocyte growth factor (HGF)-induced ERK phosphorylation and HepG2 cell migration (Lin et al., 2016). Interestingly, there are discrepancies among the recent studies concerning the expression levels and molecular roles of HSP60 in HCC. For instance, one study reported a reduction in HSP60 expression levels in HCC tissues compared to the peritumor tissues (Zhang et al., 2016). Further analyses performed by this group revealed that lowered HSP60 levels were significantly linked to the tumor differentiation grade whereby downregulation of HSP60 was associated with poor prognosis. Additionally, increased HSP60 expression cancer/pericancer $(\mathrm{C} / \mathrm{P})$ ratio was associated with enhanced overall survival as confirmed in a cohort study of 107 HCC patients (Zhang et al., 2016). At the molecular level, HSP60 was found to stimulate the differentiation of BEL-7402 and SMMC7721 and inhibit the invasion of BEL-7402 and SKHep-1 HCC cell lines. Furthermore, in vivo experiments have proven that ectopic expression of HSP60 exerts significant anti-metastatic activity following inoculation into hepatic tissue of nude mice (Zhang et al., 2016). Another biological function reported was that overexpression of HSP60 has been associated with mitochondrial biogenesis as confirmed by its direct correlation to the levels of mitochondrial biogenesis markers cytochrome c oxidase subunit (COX4) and mitochondrial DNA (mtDNA) (Zhang et al., 2016). These findings are in contrast with those obtained by another group as summarized in Table 1 (Huang et al., 2018).

\section{TARGETING HSP60 IN HCC}

Recent reports highlight the perspectives of targeting HSP60 as a future tool for cancer treatment (Nakamura and Minegishi, 2013; Cappello et al., 2014; Meng et al., 2018). In fact, HSP60 inhibition has been implemented as a therapeutic strategy in various types of cancers including melanoma (Kamm et al., 2019), pancreatic cancer (Zhou et al., 2018), and ovarian cancer (Guo et al., 2019). However, few reports concerned its targeting in HCC. Although one previous study (Zhang et al., 2016), discussed in the previous section, reported contradicting roles for HSP60 in terms of apoptosis and proliferation to what is commonly known about this chaperone in most cancer types, different findings have been reported (Huang et al., 2018) (Table 1). In experiments aiming at elucidating the potential of HSP60 inhibition for HCC treatment, this group has revealed significant enhancement of cell apoptosis, reduction of cell proliferation, and downregulation of survivin upon silencing of HSP60 in two HCC cell lines (Huang et al., 2018). Interestingly, these apoptotic and anti-proliferative effects were minimal or neglected in HSP60-silenced healthy hepatocytes (Huang et al., 2018). In line with these in vitro experiments, suppression of HSP60 in hepatoma xenograft mice models using jet polyethylenimine mediated shHSP60 delivery systems (PEI/shHSP60 complexes) resulted in significant reduction of tumor volumes and weights in the shHSP60 group compared to the control group (Huang et al., 2018). On the other hand, the clinical outcomes relative to HSP60 expression were different in the respective investigating groups. While one group showed a correlation between Hsp60 expression and clinico-pathological characteristics of HCC patients, the other group revealed no significant correlation. Their conclusion was attributed to relative high expression of HS60 in both cancerous and corresponding non-cancerous hepatic tissues in HCC patients.

\section{INHIBITORS OF HSP60}

Compared with other HSPs such as HSP90 and HSP70, few compounds have been known to target HSP60 in the oncology 
field (Nakamura and Minegishi, 2013). Recent reports have shed the light on the potential HSP60 inhibitors and their usage for cancer therapeutic purposes (Meng et al., 2018). According to their mechanism of action, HSP60 inhibitors have been classified into type I inhibitors and type II inhibitors. Type I inhibitors act by blocking the ATP binding site of
HSP60 and subsequently interfering with ATP hydrolysis and folding activities, whereas Type II compounds function through covalent interaction with specific cysteine residues within the HSP60 molecule. Nevertheless, full understanding of the exact mechanisms of HSP60 inhibitors is still lacking (Meng et al., 2018). Table 2 provides an overview about the known HSP60

TABLE 1 | Highlights of the two contradicting studies concerning HSP6O roles in HCC.

\begin{tabular}{|c|c|c|}
\hline HSP60 main function & HSP60 functions as tumor suppressor of $\mathrm{HCC}^{\mathrm{a}}$ & $\begin{array}{l}\text { HSP60 supports the development and progression of } \\
\text { HCC }^{\text {b }}\end{array}$ \\
\hline HSP60 levels & $\begin{array}{l}\text { Both mRNA and protein levels are reduced in tumor tissues } \\
\text { of HCC patients compared with peritumor tissues }\end{array}$ & $\begin{array}{l}\text { In liver tissues of HCC patients, high levels of HSP60 were } \\
\text { found in } 56.6 \% \text { of specimens compared to } 40.0 \% \text { with } \\
\text { reduced HSP60 levels }\end{array}$ \\
\hline Clinical correlation & $\begin{array}{l}\text { HSP60 expression ratio in cancerous and pericancerous } \\
\text { tissues of HCC patients [expressed as cancer/pericancer } \\
\text { (C/P) ratio] is associated with overall survival. Low ratio is } \\
\text { linked to poor overall survival and vice versa }\end{array}$ & $\begin{array}{l}\text { No significant correlation between the quantitative } \\
\text { variations of HSP60 expressed as paired tumor/non-tumor } \\
\text { ratio }(\mathrm{T} / \mathrm{N}) \text { ratio and the clinical outcomes Only elevated } \\
\text { HSP60 expression levels in non-cancerous tissues were } \\
\text { associated with shorter overall survival. Moreover, there } \\
\text { exists a positive correlation between HSP60 expression in } \\
\text { non- cancerous tissues and macrovascular invasion, high } \\
\text { tumor grades, and large tumor size }\end{array}$ \\
\hline In vivo findings & $\begin{array}{l}\text { Ectopic expression of Hsp60 in the left hepatic lobes of } \\
\text { nude mice stimulated the differentiation and suppressed } \\
\text { both intrahepatic and lung metastasis }\end{array}$ & $\begin{array}{l}\text { Targeting HSP60 in mice xenograft models by } \\
\text { jetPEI/HSP60-shRNA revealed significant reduction in both } \\
\text { tumor size and weight compared to the control group }\end{array}$ \\
\hline \multirow[t]{5}{*}{ Molecular roles of HSP60 in HCC cells } & HSP60 induced differentiation & Its role in differentiation was not experimentally investigated \\
\hline & HSP60 inhibited invasion and metastasis & Its role in metastasis was not experimentally investigated \\
\hline & HSP60 promotes mitochondrial biogenesis & $\begin{array}{l}\text { No significant alterations in mitochondrial mass upon } \\
\text { HSP60-silencing in HCC cells }\end{array}$ \\
\hline & No effect on proliferation & $\begin{array}{l}\text { HSP60 silencing resulted in marked suppression of cell } \\
\text { growth and proliferation }\end{array}$ \\
\hline & No effect on apoptosis & $\begin{array}{l}\text { HSP60 silencing destabilized survivin and promoted cell } \\
\text { death }\end{array}$ \\
\hline Conclusion & $\begin{array}{l}\text { Hsp60 exerts a tumor suppressor function, and might be } \\
\text { utilized as a potential therapeutic target in the treatment of } \\
\text { HCC }\end{array}$ & $\begin{array}{l}\text { HSP60 can serve as prognostic marker as well as a } \\
\text { therapeutic target for HCC }\end{array}$ \\
\hline
\end{tabular}

a,b Studies performed by Zhang et al. (2016) and Huang et al. (2018), respectively.

TABLE 2 | Summary of known HSP60 inhibitors ${ }^{a}$.

\begin{tabular}{|c|c|c|c|}
\hline Class & Inhibitor & Effect & References \\
\hline & Mizoribine & $\begin{array}{l}\text { Binds to the HSP60 ATPase domain and inhibits } \\
\text { the chaperoning activity of Hsp60-Hsp10 complex }\end{array}$ & $\begin{array}{l}\text { Itoh et al., 1999; Tanabe et al., } \\
2012\end{array}$ \\
\hline \multirow[t]{5}{*}{ Natural products } & Epolactaene & $\begin{array}{l}\text { Inhibits the chaperone activity of HSP60 with yet } \\
\text { unclear mechanism }\end{array}$ & $\begin{array}{l}\text { Nagumo et al., 2005; Meng } \\
\text { et al., } 2018\end{array}$ \\
\hline & ETB (tert-butyl ester of epolactaene) & $\begin{array}{l}\text { Interacts with Cys } 442 \text { of HSP60 leading to potential } \\
\text { allosteric modulation of the ATP binding pocket }\end{array}$ & Nagumo et al., 2005 \\
\hline & Myrtucommulone A (MC) & $\begin{array}{l}\text { Interacts directly with HSP60 leading to aggregation } \\
\text { and misfolding of cancer related proteins }\end{array}$ & Wiechmann et al., 2017 \\
\hline & Stephacidin B & Performs anticancer activities & $\begin{array}{l}\text { Qian-Cutrone et al., 2002; Wulff } \\
\text { et al., } 2007\end{array}$ \\
\hline & Avrainvillamide & Anticancer activities & Fenical et al., 2000 \\
\hline \multirow[t]{2}{*}{ Synthetic compounds } & O-carboranylphenoxyacetanilide & $\begin{array}{l}\text { Binds to HSP60 and inhibits the hypoxia-inducible } \\
\text { factor (HIF) activation }\end{array}$ & Ban et al., 2010 \\
\hline & $\begin{array}{l}\text { Gold (III) porphyrin complexes such as A } \\
\text { prototype gold (III) complex [Au(TPP)Cl] (10) }\end{array}$ & $\begin{array}{l}\text { Despite its poorly understood mechanisms, it } \\
\text { suppresses HSP60 and performs significant } \\
\text { anticancer activities }\end{array}$ & $\begin{array}{l}\text { Lease et al., 2013; Teo et al., } \\
\text { 2014; Hu et al., } 2016\end{array}$ \\
\hline
\end{tabular}

aNakamura and Minegishi, 2013; Meng et al., 2018. 
inhibitors which might be used in future HCC studies or combination therapies for cancer treatment.

\section{CONCLUSION AND PERSPECTIVES}

The enigma of HSP60 as a tumor suppressor or oncogenic molecule in HCC still exists. If we consider previous studies on the benefits of HSP60 targeting in variant cancer types such as in melanoma and ovarian cancer, we encourage further investigations aiming at finding ways to treat $\mathrm{HCC}$ by using drugs targeted at HSP60, to inhibit it if oncogenic or to potentiate it if anti-tumor. Since many HSP60 inhibitors are currently known and the list is still growing, several in vitro and in vivo studies are primarily and extensively needed to evaluate these inhibitors and their efficacy in HCC treatment regimens.

\section{REFERENCES}

Abd El-Salam, F. M., El-Sharqawy, E. H., El-feky, H. M., Mohammed, S. A., and Edres, A. M. (2017). Heat shock protein 60 and chromatin assembly factor-1 mRNA levels in hepatitis $C$ virus-related hepatocellular carcinoma and clinical significance. Int. J. Res. Med. Sci. 5:965. doi: 10.18203/2320-6012. ijrms20170644

Azem, A., Diamant, S., Kessel, M., Weiss, C., and Goloubinoff, P. (1995). The protein-folding activity of chaperonins correlates with the symmetric GroEL14(GroES7)2 heterooligomer. Proc. Natl. Acad. Sci. U.S.A. 92, 1202112025. doi: 10.1073/pnas.92.26.12021

Ban, H. S., Shimizu, K., Minegishi, H., and Nakamura, H. (2010). Identification of HSP60 as a primary target of o-carboranylphenoxyacetanilide, an HIF-1alpha inhibitor. J. Am. Chem. Soc. 132, 11870-11871. doi: 10.1021/ja104739t

Bray, F., Ferlay, J., Soerjomataram, I., Siegel, R. L., Torre, L. A., and Jemal, A. (2018). Global cancer statistics 2018: GLOBOCAN estimates of incidence and mortality worldwide for 36 cancers in 185 countries. CA. Cancer J. Clin. 68, 394-424. doi: 10.3322/caac.21492

Bross, P., Magnoni, R., and Bie, A. S. (2012). Molecular chaperone disorders: defective Hsp60 in neurodegeneration. Curr. Top. Med. Chem. 12, 2491-2503. doi: $10.2174 / 1568026611212220005$

Cappello, F., Conway De Macario, E., Marasà, L., Zummo, G., and Macario, A. J. L. (2008). Hsp60 expression, new locations, functions and perspectives for cancer diagnosis and therapy. Cancer Biol. Ther. 7, 801-809. doi: 10.4161/cbt.7.6. 6281

Cappello, F., Di Stefano, A., D’Anna, S. E., Donner, C. F., and Zummo, G. (2005). Immunopositivity of heat shock protein 60 as a biomarker of bronchial carcinogenesis. Lancet. Oncol. 6:816. doi: 10.1016/S1470-2045(05)70393-70394

Cappello, F., Marino Gammazza, A., Palumbo Piccionello, A., Campanella, C., Pace, A., Conway de Macario, E., et al. (2014). Hsp60 chaperonopathies and chaperonotherapy: targets and agents. Expert Opin. Ther. Targets 18, 185-208. doi: $10.1517 / 14728222.2014 .856417$

Castilla, C., Congregado, B., Conde, J. M., Medina, R., Torrubia, F. J., Japón, M. A., et al. (2010). Immunohistochemical expression of Hsp60 correlates with tumor progression and hormone resistance in prostate cancer. Urology 76, 1017.e1-1017.e6. doi: 10.1016/j.urology.2010.05.045

Chaiwatanasirikul, K.-A., and Sala, A. (2011). The tumour-suppressive function of CLU is explained by its localisation and interaction with HSP60. Cell Death Dis. 2:e219. doi: 10.1038/cddis.2011.99

Chandra, D., Choy, G., and Tang, D. G. (2007). Cytosolic accumulation of HSP60 during apoptosis with or without apparent mitochondrial release: evidence that its pro-apoptotic or pro-survival functions involve differential interactions with caspase-3. J. Biol. Chem. 282, 31289-31301. doi: 10.1074/jbc.M702777200

Chatterjee, S., and Burns, T. F. (2017). Targeting heat shock proteins in cancer: a promising therapeutic approach. Int. J. Mol. Sci. 18:2017. doi: 10.3390/ ijms 18091978

\section{AUTHOR CONTRIBUTIONS}

$\mathrm{AH}, \mathrm{SR}$, and $\mathrm{HN}$ conceived the review topic. $\mathrm{AH}$ wrote the review draft and designed the figures. $\mathrm{SR}$ and $\mathrm{HN}$ edited and revised the review draft. All authors approved the final version of the review.

\section{FUNDING}

This publication was supported by the Deutsche Forschungsgemeinschaft (DFG), Bonn, Germany, and the University of Veterinary Medicine Hannover, Foundation within the funding program Open Access Publishing. AH was supported by a scholarship from the German Academic Exchange Service (DAAD), Bonn, Germany.

Chen, B., Feder, M. E., and Kang, L. (2018). Evolution of heat-shock protein expression underlying adaptive responses to environmental stress. Mol. Ecol. 27, 3040-3054. doi: 10.1111/mec. 14769

Chen, Y., Li, X., and Shao, S. (2019). The clinical value of HSP60 in digestive system cancers: a systematic review and meta-analysis. Clin. Lab. 65:523. doi: 10.7754/Clin.Lab.2019.190523

Chun, J. N., Choi, B., Lee, K. W., Lee, D. J., Kang, D. H., Lee, J. Y., et al. (2010). Cytosolic Hsp60 is involved in the NF-kappaB-dependent survival of cancer cells via IKK regulation. PLoS One 5:e9422. doi: 10.1371/journal.pone.0009422

Deocaris, C. C., Kaul, S. C., and Wadhwa, R. (2006). On the brotherhood of the mitochondrial chaperones mortalin and heat shock protein 60. Cell Stress Chaperon. 11, 116-128. doi: 10.1379/csc-144r.1

Faried, A., Sohda, M., Nakajima, M., Miyazaki, T., Kato, H., and Kuwano, H. (2004). Expression of heat-shock protein Hsp60 correlated with the apoptotic index and patient prognosis in human oesophageal squamous cell carcinoma. Eur. J. Cancer 40, 2804-2811. doi: 10.1016/j.ejca.2004.08.013

Feng, H., Zeng, Y., Whitesell, L., and Katsanis, E. (2001). Stressed apoptotic tumor cells express heat shock proteins and elicit tumor-specific immunity. Blood 97, 3505-3512. doi: 10.1182/blood.v97.11.3505

Fenical, W., Jensen, P. R., and Cheng, X. C. (2000). Avrainvillamide, a Cytotoxic Marine Natural Product, And Derivatives There of US Patent. Available at: http://patft.uspto.gov/netacgi/nph-Parser?d=PALL\&p=1\&u=\%2Fnetahtml $\%$ 2FPTO\%2Fsrchnum.htm\&r=1\&f=G\&l=50\&s1=6066635.PN.\&OS=PN/ 6066635\&RS=PN/6066635 (accessed January 20, 2020).

Fujiwara, N., Friedman, S. L., Goossens, N., and Hoshida, Y. (2018). Risk factors and prevention of hepatocellular carcinoma in the era of precision medicine. J. Hepatol. 68, 526-549. doi: 10.1016/j.jhep.2017.09.016

Ghosh, J. C., Siegelin, M. D., Dohi, T., and Altieri, D. C. (2010). Heat shock protein 60 regulation of the mitochondrial permeability transition pore in tumor cells. Cancer Res. 70, 8988-8993. doi: 10.1158/0008-5472.CAN-10-2225

Ghouri, Y. A., Mian, I., and Rowe, J. H. (2017). Review of hepatocellular carcinoma: epidemiology, etiology, and carcinogenesis. J. Carcinog. 16:1. doi: 10.4103/jcar. JCar_9_16

Guo, J., Li, X., Zhang, W., Chen, Y., Zhu, S., Chen, L., et al. (2019). HSP60-regulated mitochondrial proteostasis and protein translation promote tumor growth of ovarian cancer. Sci. Rep. 9:12628. doi: 10.1038/s41598-019-48992-48997

Gupta, R. S., Ramachandra, N. B., Bowes, T., and Singh, B. (2008). Unusual cellular disposition of the mitochondrial molecular chaperones Hsp60, Hsp70 and Hsp10. Novartis Found. Symp. 291, 59-68. doi: 10.1002/9780470754030.ch5

Hamelin, C., Cornut, E., Poirier, F., Pons, S., Beaulieu, C., Charrier, J.-P., et al. (2011). Identification and verification of heat shock protein 60 as a potential serum marker for colorectal cancer. FEBS J. 278, 4845-4859. doi: 10.1111/j. 1742-4658.2011.08385.x

Hamrita, B., Chahed, K., Kabbage, M., Guillier, C. L., Trimeche, M., Chaïeb, A., et al. (2008). Identification of tumor antigens that elicit a humoral immune response in breast cancer patients' sera by serological proteome 
analysis (SERPA). Clin. Chim. Acta. 393, 95-102. doi: 10.1016/j.cca.2008. 03.017

Hansen, J. J., Bross, P., Westergaard, M., Nielsen, M. N., Eiberg, H., Børglum, A. D., et al. (2003). Genomic structure of the human mitochondrial chaperonin genes: HSP60 and HSP10 are localised head to head on chromosome 2 separated by a bidirectional promoter. Hum. Genet. 112, 71-77. doi: 10.1007/s00439-0020837-839

Hartl, F. U., Bracher, A., and Hayer-Hartl, M. (2011). Molecular chaperones in protein folding and proteostasis. Nature 475, 324-332. doi: 10.1038/ nature 10317

Hemmingsen, S. M., Woolford, C., van der Vies, S. M., Tilly, K., Dennis, D. T., Georgopoulos, C. P., et al. (1988). Homologous plant and bacterial proteins chaperone oligomeric protein assembly. Nature 333, 330-334. doi: 10.1038/ $333330 \mathrm{a} 0$

Henderson, B., Fares, M. A., and Lund, P. A. (2013). Chaperonin 60: a paradoxical, evolutionarily conserved protein family with multiple moonlighting functions. Biol. Rev. Camb. Philos. Soc. 88, 955-987. doi: 10.1111/brv.12037

Hipp, M. S., Kasturi, P., and Hartl, F. U. (2019). The proteostasis network and its decline in ageing. Nat. Rev. Mol. Cell Biol. 20, 421-435. doi: 10.1038/s41580019-0101-y

Hjerpe, E., Egyhazi, S., Carlson, J., Stolt, M. F., Schedvins, K., Johansson, H., et al. (2013). HSP60 predicts survival in advanced serous ovarian cancer. Int. J. Gynecol. Cancer 23, 448-455. doi: 10.1097/IGC.0b013e318284308b

Hoter, A., and Naim, H. Y. (2019). Heat shock proteins and ovarian cancer: important roles and therapeutic opportunities. Cancers 11:1389. doi: 10.3390/ cancers11091389

Hoter, A., Rizk, S., and Naim, H. Y. (2019). The multiple roles and therapeutic potential of molecular chaperones in prostate cancer. Cancers 11:1194. doi: 10.3390/cancers 11081194

Hu, D., Liu, Y., Lai, Y.-T., Tong, K.-C., Fung, Y.-M., Lok, C.-N., et al. (2016). Anticancer gold(III) porphyrins target mitochondrial chaperone Hsp60. Angew. Chem. Int. Ed. Engl. 55, 1387-1391. doi: 10.1002/anie.201509612

Huang, Y.-H., Lin, K.-H., Yu, J.-S., Wu, T.-J., Lee, W.-C., Chao, C. C. K., et al. (2018). Targeting HSP60 by subcutaneous injections of jetPEI/HSP60-shRNA destabilizes Cytoplasmic survivin and inhibits hepatocellular carcinoma growth. Mol. Carcinog. 57, 1087-1101. doi: 10.1002/mc.22827

Hwang, Y. J., Lee, S. P., Kim, S. Y., Choi, Y. H., Kim, M. J., Lee, C. H., et al. (2009). Expression of heat shock protein $60 \mathrm{kDa}$ is upregulated in cervical cancer. Yonsei Med. J. 50, 399-406. doi: 10.3349/ymj.2009.50. 3.399

Itoh, H., Komatsuda, A., Wakui, H., Miura, A. B., and Tashima, Y. (1999). Mammalian HSP60 is a major target for an immunosuppressant mizoribine. J. Biol. Chem. 274, 35147-35151. doi: 10.1074/jbc.274.49.35147

Jäättelä, M. (1999). Heat shock proteins as cellular lifeguards. Ann. Med. 31, 261-271. doi: 10.3109/07853899908995889

Kamm, A., Przychodzeń, P., Kuban-Jankowska, A., Marino Gammazza, A., Cappello, F., Daca, A., et al. (2019). 2-Methoxyestradiol and its combination with a natural compound, ferulic acid, induces melanoma cell death via downregulation of Hsp60 and Hsp90. J. Oncol. 2019, 1-12. doi: 10.1155/2019/ 9293416

Kampinga, H. H., Hageman, J., Vos, M. J., Kubota, H., Tanguay, R. M., Bruford, E., et al. (2009). Guidelines for the nomenclature of the human heat shock proteins. Cell Stress Chaperon. 14, 105-111. doi: 10.1007/s12192-008-0068-67

Kang, S.-M., Kim, S.-J., Kim, J.-H., Lee, W., Kim, G.-W., Lee, K.-H., et al. (2009). Interaction of hepatitis $\mathrm{C}$ virus core protein with Hsp60 triggers the production of reactive oxygen species and enhances TNF-alpha-mediated apoptosis. Cancer Lett. 279, 230-237. doi: 10.1016/j.canlet.2009.02.003

Khalil, A. A., and James, P. (2007). Biomarker discovery: a proteomic approach for brain cancer profiling. Cancer Sci. 98, 201-213. doi: 10.1111/j.1349-7006.2007. 00374.x

Kim, W., Oe Lim, S., Kim, J.-S., Ryu, Y. H., Byeon, J.-Y., Kim, H.-J., et al. (2003). Comparison of proteome between hepatitis B virus- and hepatitis C virus-associated hepatocellular carcinoma. Clin. Cancer Res. 9, 5493-5500.

Kimura, E., Enns, R. E., Alcaraz, J. E., Arboleda, J., Slamon, D. J., and Howell, S. B. (1993). Correlation of the survival of ovarian cancer patients with mRNA expression of the 60-kD heat-shock protein HSP-60. J. Clin. Oncol. 11, 891-898. doi: 10.1200/JCO.1993.11.5.891
Koskinas, J., Winrow, V. R., Bird, G. L. A., Lau, J. Y. N., Portmann, B. C., Blake, D. R., et al. (1993). Hepatic $60-\mathrm{kD}$ heat-shock protein responses in alcoholic hepatitis. Hepatology 17, 1047-1051. doi: 10.1002/hep.1840170617

Lease, N., Vasilevski, V., Carreira, M., de Almeida, A., Sanaú, M., Hirva, P., et al. (2013). Potential anticancer heterometallic Fe-Au and Fe-Pd agents: initial mechanistic insights. J. Med. Chem. 56, 5806-5818. doi: 10.1021/jm4007615

Leitner, A., Joachimiak, L. A., Bracher, A., Mönkemeyer, L., Walzthoeni, T., Chen, B., et al. (2012). The molecular architecture of the eukaryotic chaperonin TRiC/CCT. Structure 20, 814-825. doi: 10.1016/j.str.2012.03.007

Li, X., Xu, Q., Fu, X., and Luo, W. (2014). Heat shock protein 60 overexpression is associated with the progression and prognosis in gastric cancer. PLoS One 9:e107507. doi: 10.1371/journal.pone.0107507

Lianos, G. D., Alexiou, G. A., Mangano, A., Mangano, A., Rausei, S., Boni, L., et al. (2015). The role of heat shock proteins in cancer. Cancer Lett. 360, 114-118. doi: 10.1016/j.canlet.2015.02.026

Lim, S.-O., Park, S.-G., Yoo, J.-H., Park, Y.-M., Kim, H., Jang, K., et al. (2005). Expression of heat shock proteins (HSP27, HSP60, HSP70, HSP90, GRP78, GRP94) in hepatitis B virus-related hepatocellular carcinomas and dysplastic nodules. World J. Gastroenterol. 11, 2072-2079. doi: 10.3748/wjg.v11.i14.2072

Lim, S. O., Park, S.-J., Kim, W., Park, S. G., Kim, H.-J., Kim, Y.-I., et al. (2002). Proteome analysis of hepatocellular carcinoma. Biochem. Biophys. Res. Commun. 291, 1031-1037. doi: 10.1006/bbrc.2002.6547

Lin, C.-Y., Hu, C.-T., Cheng, C.-C., Lee, M.-C., Pan, S.-M., Lin, T.-Y., et al. (2016). Oxidation of heat shock protein 60 and protein disulfide isomerase activates ERK and migration of human hepatocellular carcinoma HepG2. Oncotarget 7, 11067-11082. doi: 10.18632/oncotarget.7093

Lindquist, S., and Craig, E. A. (1988). The heat-shock proteins. Annu. Rev. Genet. 22, 631-677. doi: 10.1146/annurev.ge.22.120188.003215

Liu, K., Qian, L., Wang, J., Li, W., Deng, X., Chen, X., et al. (2009). Twodimensional blue native/SDS-PAGE analysis reveals heat shock protein chaperone machinery involved in hepatitis B virus production in HepG2.2.15 cells. Mol. Cell. Proteom. 8, 495-505. doi: 10.1074/mcp.M800250-MCP200

Lohse, A. W., Dienes, H. P., Herkel, J., Hermann, E., van Eden, W., and Meyer zum Büschenfelde, K. (1993). Expression of the $60 \mathrm{kDa}$ heat shock protein in normal and inflamed liver. J. Hepatol. 19, 159-166. doi: 10.1016/s0168-8278(05)8018980188

Looi, K. S., Nakayasu, E. S., Diaz, R. A., de Tan, E. M., Almeida, I. C., and Zhang, J.-Y. (2008). Using proteomic approach to identify tumor-associated antigens as markers in hepatocellular carcinoma. J. Proteome Res. 7, 4004-4012. doi: $10.1021 /$ pr800273h

Meng, Q., Li, B. X., and Xiao, X. (2018). Toward developing chemical modulators of hsp60 as potential therapeutics. Front. Mol. Biosci. 5:35. doi: 10.3389/fmolb. 2018.00035

Merendino, A. M., Bucchieri, F., Campanella, C., Marcianò, V., Ribbene, A., David, S., et al. (2010). Hsp60 is actively secreted by human tumor cells. PLoS One 5:e9247. doi: 10.1371/journal.pone.0009247

Nagumo, Y., Kakeya, H., Shoji, M., Hayashi, Y., Dohmae, N., and Osada, H. (2005). Epolactaene binds human Hsp60 Cys442 resulting in the inhibition of chaperone activity. Biochem. J. 387, 835-840. doi: 10.1042/BJ20041355

Nakamura, H., and Minegishi, H. (2013). HSP60 as a drug target. Curr. Pharm. Des. 19, 441-451. doi: 10.2174/13816128130310

Nisemblat, S., Yaniv, O., Parnas, A., Frolow, F., and Azem, A. (2015). Crystal structure of the human mitochondrial chaperonin symmetrical football complex. Proc. Natl. Acad. Sci. U.S.A. 112, 6044-6049. doi: 10.1073/pnas. 1411718112

Niu, B., and Hann, H.-W. (2017). "Hepatitis B virus-related hepatocellular carcinoma: carcinogenesis, prevention, and treatment," in Updates in Liver Cancer, Vol. 13, ed. H. Abdeldayem (London: IntechOpen), doi: 10.5772/ 65424, Available online at: https://www.intechopen.com/books/updates-inliver-cancer

Okamoto, T., Ishida, R., Yamamoto, H., Tanabe-Ishida, M., Haga, A., Takahashi, H., et al. (2015). Functional structure and physiological functions of mammalian wild-type HSP60. Arch. Biochem. Biophys. 586, 10-19. doi: 10.1016/j.abb.2015. 09.022

Pace, A., Barone, G., Lauria, A., Martorana, A., Piccionello, A. P., Pierro, P. et al. (2013). Hsp60, a novel target for antitumor therapy: structure-function features and prospective drugs design. Curr. Pharm. Des. 19, 2757-2764. doi: $10.2174 / 1381612811319150011$ 
Park, S. G., and Jung, G. (2001). Human hepatitis B virus polymerase interacts with the molecular chaperonin Hsp60. J. Virol. 75, 6962-6968. doi: 10.1128/JVI.75. 15.6962-6968.2001

Park, S. G., Lee, S. M., and Jung, G. (2003). Antisense oligodeoxynucleotides targeted against molecular chaperonin Hsp60 block human hepatitis B virus replication. J. Biol. Chem. 278, 39851-39857. doi: 10.1074/jbc.M30161 8200

Park, S. G., Lim, S. O., and Jung, G. (2002). Binding site analysis of human HBV pol for molecular chaperonin, hsp60. Virology 298, 116-123. doi: 10.1006/viro. 2002.1496

Qian-Cutrone, J., Huang, S., Shu, Y.-Z., Vyas, D., Fairchild, C., Menendez, A., et al. (2002). Stephacidin A and B: two structurally novel, selective inhibitors of the testosterone-dependent prostate LNCaP cells. J. Am. Chem. Soc. 124, 14556-14557. doi: 10.1021/ja028538n

Rodríguez, M. E., Cogno, I. S., Milla Sanabria, L. S., Morán, Y. S., and Rivarola, V. A. (2016). Heat shock proteins in the context of photodynamic therapy: autophagy, apoptosis and immunogenic cell death. Photochem. Photobiol. Sci. 15, 1090-1102. doi: 10.1039/c6pp00097e

Ruan, W., Wang, Y., Ma, Y., Xing, X., Lin, J., Cui, J., et al. (2010). HSP60, a protein downregulated by IGFBP7 in colorectal carcinoma. J. Exp. Clin. Cancer Res. 29, 41. doi: 10.1186/1756-9966-29-41

Samali, A., Cai, J., Zhivotovsky, B., Jones, D. P., and Orrenius, S. (1999). Presence of a pre-apoptotic complex of pro-caspase-3, Hsp60 and Hsp10 in the mitochondrial fraction of jurkat cells. EMBO J. 18, 2040-2048. doi: 10.1093/ emboj/18.8.2040

Sapozhnikov, A. M., Ponomarev, E. D., Tarasenko, T. N., and Telford, W. G. (1999). Spontaneous apoptosis and expression of cell surface heat-shock proteins in cultured EL-4 lymphoma cells. Cell Prolif. 32, 363-378. doi: 10.1111/j.13652184.1999.tb01354.x

Soltys, B. J., and Gupta, R. S. (1999). Mitochondrial-matrix proteins at unexpected locations: are they exported? Trends Biochem. Sci. 24, 174-177. doi: 10.1016/ s0968-0004(99)01390-1390

Sørensen, J. G., Kristensen, T. N., and Loeschcke, V. (2003). The evolutionary and ecological role of heat shock proteins. Ecol. Lett. 6, 1025-1037. doi: 10.1046/j. 1461-0248.2003.00528.x

Stasi, C., Silvestri, C., Voller, F., and Cipriani, F. (2016). The epidemiological changes of HCV and HBV infections in the era of new antiviral therapies and the anti-HBV vaccine. J. Infect. Public Health 9, 389-395. doi: 10.1016/j.jiph. 2015.05.004

Tanabe, M., Ishida, R., Izuhara, F., Komatsuda, A., Wakui, H., Sawada, K., et al. (2012). The ATPase activity of molecular chaperone HSP60 is inhibited by immunosuppressant mizoribine. Am. J. Mol. Biol. 2, 93-102. doi: 10.4236/ajmb. 2012.22010

Teo, R. D., Gray, H. B., Lim, P., Termini, J., Domeshek, E., and Gross, Z. (2014). A cytotoxic and cytostatic gold(III) corrole. Chem. Commun. 50, 13789-13792. doi: $10.1039 / \mathrm{c} 4 \mathrm{cc} 06577 \mathrm{~h}$
Tsai, Y.-P., Yang, M.-H., Huang, C.-H., Chang, S.-Y., Chen, P.-M., Liu, C.-J., et al. (2009). Interaction between HSP60 and beta-catenin promotes metastasis. Carcinogenesis 30, 1049-1057. doi: 10.1093/carcin/bgp087

Wiechmann, K., Müller, H., König, S., Wielsch, N., Svatoš, A., Jauch, J., et al. (2017). Mitochondrial chaperonin HSP60 is the apoptosis-related target for myrtucommulone. Cell Chem. Biol. 24, 614.e-623.e. doi: 10.1016/j.chembiol. 2017.04.008

Winrow, V. R., Bird, G. L., Koskinas, J., Blake, D. R., Williams, R., and Alexander, G. J. M. (1994). Circulating IgA antibody against a $65 \mathrm{kDa}$ heat shock protein in acute alcoholic hepatitis. J. Hepatol. 20, 359-363. doi: 10.1016/s0168-8278(94) 80008-80001

Wu, J., Liu, T., Rios, Z., Mei, Q., Lin, X., and Cao, S. (2017). Heat Shock Proteins and Cancer. Trends Pharmacol. Sci. 38, 226-256. doi: 10.1016/j.tips.2016.11.009

Wulff, J. E., Herzon, S. B., Siegrist, R., and Myers, A. G. (2007). Evidence for the rapid conversion of stephacidin B into the electrophilic monomer avrainvillamide in cell culture. J. Am. Chem. Soc. 129, 4898-4899. doi: 10.1021/ ja0690971

Xanthoudakis, S., Roy, S., Rasper, D., Hennessey, T., Aubin, Y., Cassady, R., et al. (1999). Hsp60 accelerates the maturation of pro-caspase-3 by upstream activator proteases during apoptosis. EMBO J. 18, 2049-2056. doi: 10.1093/ emboj/18.8.2049

Xu, H.-Z., Liu, Y.-P., Guleng, B., and Ren, J.-L. (2014). Hepatitis B virus-related hepatocellular carcinoma: pathogenic mechanisms and novel therapeutic interventions. Gastrointest. Tumor. 1, 135-145. doi: 10.1159/000365307

Zhang, J., Zhou, X., Chang, H., Huang, X., Guo, X., Du, X., et al. (2016). Hsp60 exerts a tumor suppressor function by inducing cell differentiation and inhibiting invasion in hepatocellular carcinoma. Oncotarget 7, 68976-68989. doi: 10.18632/oncotarget.12185

Zhang, S. M., Sun, D. C., Lou, S., Bo, X. C., Lu, Z., Qian, X. H., et al. (2005). HBx protein of hepatitis B virus (HBV) can form complex with mitochondrial HSP60 and HSP70. Arch. Virol. 150, 1579-1590. doi: 10.1007/s00705-005-0521-521

Zhou, C., Sun, H., Zheng, C., Gao, J., Fu, Q., Hu, N., et al. (2018). Oncogenic HSP60 regulates mitochondrial oxidative phosphorylation to support Erk1/2 activation during pancreatic cancer cell growth. Cell Death Dis. 9:161. doi: 10.1038/s41419-017-0196-z

Conflict of Interest: The authors declare that the research was conducted in the absence of any commercial or financial relationships that could be construed as a potential conflict of interest.

Copyright (c) 2020 Hoter, Rizk and Naim. This is an open-access article distributed under the terms of the Creative Commons Attribution License (CC BY). The use, distribution or reproduction in other forums is permitted, provided the original author(s) and the copyright owner(s) are credited and that the original publication in this journal is cited, in accordance with accepted academic practice. No use, distribution or reproduction is permitted which does not comply with these terms. 